\title{
Manejo de plantas de cobertura no controle de plantas daninhas e desempenho produtivo da cultura do milho
}

\author{
Cover crop management in the weed control and productive \\ performance in corn
}

\author{
Pedro Valério Dutra de Moraes ${ }^{1 *}$; Dirceu Agostinetto2; Luis Eduardo Panozzo; \\ Claudia Oliveira ${ }^{4}$; Gerson Kleinick Vignolo ${ }^{5}$; Catarine Markus ${ }^{6}$
}

\begin{abstract}
Resumo
Objetivou-se avaliar espécies vegetais com potencial alelopático, associados às práticas de manejo e ao uso de herbicida nicosulfuron, no controle de plantas daninhas e nos componentes de produtividade da cultura do milho. $\mathrm{O}$ delineamento experimental utilizado foi em blocos ao acaso, com quatro repetições. $\mathrm{O}$ experimento foi composto por três fatores: espécies de cobertura, manejo das coberturas e aplicação ou não de herbicida nicosulfuron em pós-emergência. As variáveis avaliadas foram: número de plantas daninhas, número de fileiras de grãos, número de grãos por fileira, número de grãos por espiga e produtividade de grãos de milho. A cobertura de azevém, em geral, reduz o número de plantas daninhas emergidas e favorece o desempenho produtivo do milho. O manejo das plantas de cobertura com roçada e retirada da palha reduz a produtividade do milho. A maior produtividade do milho, foi observada com a aplicação de nicosulfuron em pós-emergência, independente da cultura de cobertura ou do manejo adotado.
\end{abstract}

Palavras-chave: Alelopatia, Raphanus sativus, Lolium multiflorum, Trifolium vesiculosum

\begin{abstract}
The objective of the study was evaluate the allelopathy of cover species, associated to management practices and use of nicosulfuron herbicide on the productive performance of corn. The experimental design consisted of complete randomized block with four replications. The treatments were: cover species, cover management and application or not of post-emergence herbicide. The variables evaluated were: number of weeds, number of rows kernels, number of kernels rows, number of kernels ear and grain yield of corn. Lolium multiflorum, reduced the number of emerged weeds and provides the best results in productive performance. The management simulated grazing, does not favor the yield of corn. The application of nicosulfuron in post-emergence, along with the allelopathic activity increases the productive performance of corn, regardless of cover crop or soil management.

Key words: Allelopathy, Raphanus sativus, Lolium multiflorum, Trifolium vesiculosum
\end{abstract}

${ }^{1}$ Prof. D.Sc. do Dept $^{\circ}$ de Agronomia, Universidade Tecnológica Federal do Paraná, UTFPR, Dois Vizinhos, PR. E-mail: pedromoraes@utfpr.edu.br

2 Prof. D.Sc. do Dept ${ }^{\mathrm{o}}$ de Fitossanidade, Faculdade de Agronomia Eliseu Maciel, UFPeL, Pelotas, RS. Bolsista em produtividade do CNPq. E-mail: agostinetto@ig.com.br

${ }^{3} \mathrm{Eng}^{\mathrm{o}} \mathrm{Agr}^{\mathrm{o}}$, D.Sc. em Fitotecnia, UFV, Colaborador do Setor de Agroenergia da Embrapa Clima Temperado, Pelotas, RS. E-mail: lepanozzo@gmail.com

${ }^{4}$ Eng $^{\mathrm{a}}$ Agr ${ }^{\mathrm{a}}$, Discente de Mestrado do Dept ${ }^{\circ}$ de Fitossanidade, Universidade Federal de Pelotas, UFPel, Pelotas, RS. E-mail: oliveirac.agro@gmail.com

5 Eng $^{\circ}$ Agr $^{\circ}$, Discente de Doutorado de Dept ${ }^{\circ}$ de Agronomia, UFPel, Pelotas, RS. E-mail: gerson_vignolo@yahoo.com.br

${ }^{6}$ Eng $^{\text {a }}$ Agr $^{\mathrm{a}}$, Discente de Mestrado do Dept ${ }^{\circ}$ de Fitotecnia, Universidade Federal do Rio Grande do Sul, UFRGS, Porto Alegre, RS. E-mail: catarine.markus@gmail.com

* Autor para correspondência

Recebido para publicação 12/09/11 Aprovado em 13/02/13 


\section{Introdução}

O milho é utilizado como fonte energética na alimentação humana e principalmente, para alimentação animal, o que corresponde a 70\% da demanda mundial (JASPER et al., 2009) e, é especialmente cultivado em sistemas de produção mais tecnificados, baseados na semeadura direta e na rotação de culturas (PALHARES, 2003).

A redução da produtividade da cultura do milho devida à competição estabelecida com as plantas daninhas pode alcançar até $70 \%$ da sua produtividade potencial, variando em função da espécie e do grau de infestação das plantas daninhas e de fatores ambientais (FANCELLI; DOURADONETO, 2000). Deste modo, o uso de plantas de cobertura em sistema de semeadura direta tem aumentado, por ser um importante componente de práticas agriculturais, que ajuda na redução das perdas de solo e água e no controle de plantas daninhas (MAIGHANY et al., 2007; CALVO; FOLONI; BRANCALIÃO, 2010).

O desenvolvimento da cultura do milho, assim como das plantas daninhas, pode ser alterado pela alelopatia presente nas culturas de cobertura de solo em sistema de semeadura direta. Resíduos de culturas de cobertura usadas para aumentar a fertilidade do solo e controlar plantas daninhas, também podem suprimir a germinação e o crescimento das culturas, pela presença de aleloquímicos (LIEBMAN; SUNDBERG, 2006), ou pelos efeitos físicos gerados pela cobertura de solo (MONQUERO et al., 2009).

Estudos relatam que atividade alelopática em coberturas de trevo-vermelho (LIEBMAN; SUNDBERG, 2006), leucena (PRATES et al., 2000), aveia, milheto, trigo, nabo, colza (TOKURA; NÓBREGA, 2005) e capim-braquiária (SOUZA et al., 2006), podem afetar o crescimento de várias plantas daninhas e culturas, entre elas o milho.

A escolha da adequada espécie de cobertura de solo, assim como o seu correto manejo, pode trazer benefícios no controle de plantas daninhas e ao desenvolvimento da cultura do milho. O potencial alelopático das culturas de cobertura depende do tipo de resíduo que permanece sobre o solo e das plantas daninhas e/ou cultura que nele se desenvolvem (TOKURA; NÓBREGA, 2006; MONQUERO et al., 2009).

O manejo das plantas de cobertura deve ser entendido como o procedimento através do qual o desenvolvimento delas éinterrompido e seus resíduos possam fazer parte da camada de palha na superfície do solo (ALVARENGA et al., 2001). A utilização de diferentes manejos modifica a fragmentação do material, alterando a decomposição e modificando as condições do meio para o milho e interferindo diretamente na liberação de aleloquímicos no ambiente (TIMOSSI; DURIGAN; LEITE, 2006).

O manejo das espécies de cobertura pode ser realizado por métodos mecânicos, químicos ou a combinação destes. O manejo mecânico, contudo, é eficiente apenas quando realizado no estádio correto de desenvolvimento da cobertura de plantas, isto é, quando a produção de massa vegetal atinge o máximo e a rebrota é reduzida. No método químico, utilizam-se basicamente herbicidas de ação total, que não possuem seletividade como o glyphosate e paraquat (ARAÚJO; RODRIGUES, 2000; FURLANI et al., 2007).

Visando assegurar uma melhor cobertura do solo, a eliminação de rebrotas da cobertura morta e seu acamamento adequado, tem sido muito usado a combinação entre os manejos químico e mecânico (ARAÚJO; RODRIGUES, 2000).

Aliado ao uso da alelopatia presente na cobertura do solo e do correto manejo da cobertura, em algumas situações há necessidade de intervenção com herbicidas em pós-emergência das plantas daninhas, para evitar a redução de produtividade da cultura em função da interferência gerada pelas mesmas (BALBINOT JUNIOR et al., 2007). Nestas situações, o uso do herbicida nicosulfuron (inibidor da acetolactato sintase - ALS) em pós-emergência da cultura do milho, pode ser importante para 
favorecer a cultura na competição com as plantas daninhas.

Este estudo teve por objetivo avaliar o efeito de espécies de cobertura de solo com potencial alelopático, associado a diferentes manejos da cobertura e ao uso de nicosulfuron, no controle de plantas daninhas e nos componentes de produtividade da cultura do milho.

\section{Material e Métodos}

O experimento foi conduzido no ano agrícola de 2006/2007, na área experimental do Centro Agropecuário da Palma (CAP), da Universidade Federal de Pelotas (UFPel), no município de Capão do Leão-RS, em solo classificado como Argissolo Vermelho Amarelo, de textura franco-arenosa (EMBRAPA, 2006), cultivado anteriormente com a cultura da soja. O delineamento experimental foi blocos ao acaso, em esquema de parcelas subsubdivididas, com quatro repetições. A área

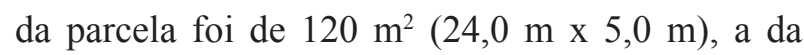
sub-parcela, $24 \mathrm{~m}^{2}(4,8 \mathrm{~m} \times 5,0 \mathrm{~m})$ e a da subsubparcela, $12 \mathrm{~m}^{2}(4,8 \mathrm{~m} \times 2,5 \mathrm{~m})$. Antes da aplicação dos tratamentos, foi determinada a massa seca das plantas de cobertura aos 145 dias após emergência (DAE), onde foi verificado $3,2 \mathrm{t} \mathrm{ha}^{-1}$ para cobertura de azevém, 3,7 t ha-1 para nabo-forrageiro, 2,6 $\mathrm{t} \mathrm{ha}^{-1}$ de trevo-vesiculoso e $2.2 \mathrm{t} \mathrm{ha}^{-1}$ para a vegetação espontânea presente no pousio.

Inicialmente o experimento foi composto por dois fatores. Nas parcelas foram estudadas quatro espécies de cobertura: azevém (Lolium multiflorum Lam); nabo-forrageiro (Raphanus sativus L.); trevo-vesiculoso (Trifolium vesiculosum Savi.); ou pousio (composto principalmente por Spergula arvense). Nas subparcelas foram avaliados cinco tipos de manejo das espécies de cobertura (roçada com retirada da palha; roçada sem retirada da palha; aplicação de glyphosate - 1440 g e.a. ha-1; aplicação de paraquat - $300 \mathrm{~g}$ i.a. ha ${ }^{-1}$; e testemunha - tombamento natural da palha, sem dessecação ou manejo), realizados no dia 24 de outubro de 2006.
A utilização de diferentes herbicidas dessecantes, modo de ação diferenciados, visou verificar se o período de tempo que cada um destes leva para controlar a planta de cobertura ou possibilita o rebrote e, assim, sua influencia na decomposição da cobertura morta.

Posteriormente, na subsubparcela foi estudada a aplicação ou não de nicossulfuron, na dose de 50 g i.a. ha ${ }^{-1}$ aos 23 DAE (dias após emergência) da cultura do milho, quando a cultura se apresentava com aproximadamente 5 folhas (2 a 3 semanas após emergência). A aplicação de nicosulfuron, foi considerado como referencial de $100 \%$ de controle para cada tratamentos da parcela e subparcela. Este herbicida foi aplicado para o controle de plantas daninhas em estádios iniciais de desenvolvimento.

A semeadura das espécies de cobertura foi realizada a lanço, em 20 de junho de 2006, utilizando 30,15 e $8 \mathrm{~kg}^{-1}$ de azevém, naboforrageiro e trevo-vesiculoso, respectivamente. A adubação foi realizada segundo análise de solo, utilizando-se 438, 375 e $344 \mathrm{~kg} \mathrm{ha}^{-1}$ de N-P-K, da fórmula 6-14-12, para azevém, nabo-forrageiro e trevo-vesiculoso, respectivamente. Para a adubação nitrogenada de azevém, utilizaram-se $264 \mathrm{~kg} \mathrm{ha}^{-1} \mathrm{de}$ nitrogênio, na forma de ureia, a qual foi fracionada em duas aplicações: $31 \mathrm{~kg} \mathrm{ha}^{-1}$ na semeadura e o restante em cobertura, aplicado no início do perfilhamento. Para a cultura do nabo-forrageiro, utilizaram-se $76 \mathrm{~kg} \mathrm{ha}^{-1}$ de nitrogênio, na forma de ureia, a qual foi fracionada em duas aplicações: $8 \mathrm{~kg} \mathrm{ha}^{-1}$ na semeadura e o restante em cobertura quando a planta apresentou quatro folhas formadas. Para a cultura de trevo-vesiculoso, não foi utilizada adubação de cobertura.

A semeadura do milho (cultivar AG 122) foi realizada 15 dias após aplicação dos manejos das coberturas de solo, onde se estabeleceu população de 70.000 plantas de milho ha-1. Para adubação de base utilizou-se $436 \mathrm{~kg} \mathrm{ha}^{-1}$ de adubo NPK na fórmula 5-30-20, complementado com $55 \mathrm{~kg}$ ha${ }^{1}$ de nitrogênio na forma de ureia. Em cobertura 
forma aplicados $222 \mathrm{~kg} \mathrm{ha}^{-1}$ fracionados quando as plantas apresentarem 40-60 cm de altura (estádio fenológico 2) e próximo ao pendoamento (estádio fenológico 4). A irrigação por aspersão foi realizada conforme necessidades da cultura. Dados referentes a precipitação acumulada e temperaturas máximas e mínimas durante o período do estabelecimento das culturas de cobertura de solo e da cultura do milho são apresentados na Tabela 1.

Tabela 1. Precipitação pluviométrica $(\mathrm{mm})$ e temperaturas máximas e nínimas $\left({ }^{\circ} \mathrm{C}\right)$ ocorridas no período de condução do experimento (2006/2007).

\begin{tabular}{|c|c|c|c|c|}
\hline $\begin{array}{c}\text { Meses de condução } \\
\text { do experimento }\end{array}$ & $\begin{array}{l}\text { Quinzena } \\
\text { do mês }\end{array}$ & $\begin{array}{c}\text { Precipitação } \\
\text { acumulada (mm) }\end{array}$ & $\begin{array}{l}\text { Temperatura } \\
\text { máxima }\left({ }^{\circ} \mathrm{C}\right)\end{array}$ & $\begin{array}{l}\text { Temperatura } \\
\text { mínima }\left({ }^{\circ} \mathrm{C}\right)\end{array}$ \\
\hline Junho & $1^{\mathrm{a}}$ quinzena & 33,4 & 20,3 & 9,6 \\
\hline 2006 & $2^{\mathrm{a}}$ quinzena & 26,8 & 19,5 & 8,3 \\
\hline Julho & $1^{a}$ quinzena & 55,6 & 21,8 & 11,4 \\
\hline 2006 & $2^{\mathrm{a}}$ quinzena & 23,6 & 22,4 & 11,8 \\
\hline Agosto & $1^{\text {a }}$ quinzena & 91,4 & 19,3 & 10,6 \\
\hline 2006 & $2^{\mathrm{a}}$ quinzena & 18,4 & 19,2 & 7,7 \\
\hline Setembro & $1^{\text {a }}$ quinzena & 86,8 & 18,9 & 8,6 \\
\hline 2006 & $2^{\mathrm{a}}$ quinzena & 2,4 & 20,6 & 10,6 \\
\hline Outubro & $1^{\mathrm{a}}$ quinzena & 44,6 & 22,9 & 14,2 \\
\hline 2006 & $2^{\mathrm{a}}$ quinzena & 8,3 & 26,4 & 15,5 \\
\hline Novembro & $1^{\mathrm{a}}$ quinzena & 7,9 & 24,7 & 14,0 \\
\hline 2006 & $2^{\mathrm{a}}$ quinzena & 51,8 & 24,9 & 15,9 \\
\hline Dezembro & $1^{\mathrm{a}}$ quinzena & 35,4 & 28,9 & 18,0 \\
\hline 2006 & $2^{\mathrm{a}}$ quinzena & 104,8 & 31,6 & 21,0 \\
\hline Janeiro & $1^{\mathrm{a}}$ quinzena & 6,4 & 30,1 & 20,2 \\
\hline 2007 & $2^{\mathrm{a}}$ quinzena & 5,4 & 31,3 & 19,8 \\
\hline Fevereiro & $1^{\mathrm{a}}$ quinzena & 54,4 & 30,5 & 17,7 \\
\hline 2007 & $2^{\mathrm{a}}$ quinzena & 38,2 & 25,9 & 16,9 \\
\hline Março & $1^{\text {a }}$ quinzena & 57,8 & 29,0 & 20,5 \\
\hline 2007 & $2^{\mathrm{a}}$ quinzena & 145,2 & 29,7 & 21,0 \\
\hline Abril & $1^{\mathrm{a}}$ quinzena & 89,6 & 25,6 & 16,5 \\
\hline 2007 & $2^{\mathrm{a}}$ quinzena & 54,9 & 25,8 & 16,5 \\
\hline
\end{tabular}

Fonte: Elaboração dos autores com base nos dados do Boletim Agroclimatológico EMBRAPA/UFPEL/INMET.

Para a aspersão dos herbicidas utilizou-se pulverizador costal com barra contendo quatro bicos de jato plano em leque 110.02, operando em pressão constante de $210 \mathrm{Kpa}$, o que proporcionou a aplicação de um volume de calda de $150 \mathrm{~L} \mathrm{ha}^{-1}$.

Aos 45 DAE do milho, nas subsubparcelas em que não foi aplicado nicosulfuron, foi realizada a identificação por espécie e a contagem de plantas daninhas com auxílio de quadrado com 0,25 $\mathrm{m}^{2}$ de área, em dois pontos aleatórios na unidade experimental.
Ao final do ciclo da cultura colheu-se a área útil de cada unidade experimental $\left(3,6 \mathrm{~m}^{2}\right)$, onde foram avaliados o desempenho produtivo da cultura do milho: número de fileira de grãos (NFG), número de grãos por fileiras (NGF), número de grãos por espiga (NGE) e produtividade de grãos de milho. O NGE foi estimado pelo número de fileiras e pelo número de grãos em cinco fileiras. A produtividade foi estabelecida em $\mathrm{kg} \mathrm{ha}{ }^{-1}$, após correção da umidade dos grãos para $13 \%$. 
Os dados foram analisados com relação a sua homogeneidade e então submetidos à análise de variância por do teste $\mathrm{F}$ e, nos casos de significância estatística, foi procedida a comparação entre médias; para os fatores culturas de cobertura e manejo da cobertura, utilizou-se o teste de Tukey $(p \leq 0,05)$ e para o fator aplicação do herbicida nicosulfuron, o teste $\mathrm{t}(\mathrm{p} \leq 0,05)$.

\section{Resultados e Discussão}

Para o número de plantas daninhas, não houve interação entre as culturas de coberturas e manejo adotado (Tabelas 2 e 3). As principais espécies de plantas daninhas emergidas na área experimental foram Digitaria spp. (milhã, capim-colchão), Brachiaria plantaginea (papuã, capim-marmelada),
Bidens sp. (picão-preto) e Richaridia brasiliensis (poaia-branca).

O número de plantas daninhas variou em função das coberturas, sendo que a cobertura de azevém, em geral, proporcionou maior redução das plantas daninhas avaliadas (Tabela 2). Estes resultados podem decorrer da espécie produzir diferentes compostos alelopáticos, que inibem a germinação e o desenvolvimento de plantas daninhas (BUENO; AMIAMA; HERNANZ, 2007). Entretanto, segundo Gomes Junior e Christoffoleti (2008), dependendo da espécie de cobertura e da quantidade de palhada existente sobre o solo, o controle das plantas daninhas pode ocorrer devido à atividade alelopática e/ou com a formação de barreira física, impedindo a sobrevivência das sementes germinadas na superfície do solo.

Tabela 2. Número de plantas daninhas emergidas $\left(\mathrm{m}^{2}\right)$, em função das coberturas de solo aos 45 dias após emergência da cultura do milho (70.000 plantas ha-1)

\begin{tabular}{lcccc}
\hline \multirow{2}{*}{\multicolumn{1}{c}{ Culturas }} & \multicolumn{4}{c}{ Número médio de plantas daninhas $\left(\mathrm{m}^{2}\right)$} \\
\cline { 2 - 5 } de cobertura & Digitaria spp. & Brachiaria plantaginea & Bidens $\mathrm{sp}$. & Richaridia brasiliensis \\
\hline Lolium multiflorum & $4,8 \mathrm{bc}$ & $0,9 \mathrm{ab}$ & $0,0 \mathrm{~b}$ & $0,1 \mathrm{c}$ \\
Raphanus sativus & $12,7 \mathrm{a}$ & $1,8 \mathrm{a}$ & $0,0 \mathrm{~b}$ & $0,2 \mathrm{bc}$ \\
Trifolium vesiculosum & $3,5 \mathrm{c}$ & $0,5 \mathrm{~b}$ & $0,2 \mathrm{ab}$ & $1,6 \mathrm{a}$ \\
Pousio & $11,9 \mathrm{ab}$ & $0,7 \mathrm{~b}$ & $0,4 \mathrm{a}$ & $1,0 \mathrm{ab}$ \\
\hline
\end{tabular}

${ }^{1}$ Médias seguidas por mesma letra minúscula na coluna não diferem entre si pelo teste de Tukey $(\mathrm{p} \leq 0,05)$.

Fonte: Elaboração dos autores.

A cobertura de nabo-forrageiro, em geral, permitiu maior desenvolvimento de plantas daninhas (Tabela 2), de modo semelhante ao verificado por Rizzardi e Silva (2006) e Balbinot Junior et al. (2007). A cobertura de nabo-forrageiro foi a espécie que proporcionou a maior porcentagem de cobertura de solo e produção de massa da matéria seca $(3,7 \mathrm{t}$ $\left.\mathrm{ha}^{-1}\right)$. Para estes autores, a razão da maior infestação de plantas daninhas é a baixa relação $\mathrm{C} / \mathrm{N}$, o que proporciona rápida decomposição, deixando o solo descoberto em pouco tempo e sem a presença dos possíveis aleloquímicos.

O número de plantas emergidas de capim- colchão e capim-marmelada não foi influenciado pelo manejo adotado nas coberturas de solo (Tabela 3). Quando não houve manejo na cobertura de solo (testemunha), picão-preto e poaia-branca, em geral, apresentaram maior número de plantas emergidas (Tabela 3). A explicação pode decorrer do menor contato da cobertura com o solo, durante o tombamento natural da cobertura, liberando consequentemente substâncias alelopáticas em menor quantidade e de forma lenta durante a decomposição. Outro fator que pode ter influenciado no maior número de plantas daninhas foi a maior incidência de luz no solo, estimulando a germinação de sementes fotoblásticas positivas. 
Tabela 3. Número de plantas daninhas emergidas $\left(\mathrm{m}^{2}\right)$, em função do manejo das coberturas de solo aos 45 dias após a emergência da cultura do milho (70.000 plantas ha $\left.{ }^{-1}\right)$

\begin{tabular}{lcccc}
\hline \multirow{1}{*}{\multicolumn{1}{c}{ Culturas }} & \multicolumn{4}{c}{ Número de plantas daninhas $\left(\mathrm{m}^{2}\right)$} \\
\cline { 2 - 5 } \multicolumn{1}{c}{ de cobertura } & Digitaria spp. & Brachiaria plantaginea & Bidens $\mathrm{sp.}$ & Richaridia brasiliensis \\
\hline Testemunha & $7,6 \mathrm{a}^{1}$ & $0,4 \mathrm{a}$ & $0,5 \mathrm{a}$ & $1,1 \mathrm{ab}$ \\
Roçado sem palha & $9,6 \mathrm{a}$ & $1,1 \mathrm{a}$ & $0,0 \mathrm{~b}$ & $1,4 \mathrm{a}$ \\
Roçado com palha & $9,1 \mathrm{a}$ & $0,9 \mathrm{a}$ & $0,1 \mathrm{ab}$ & $0,6 \mathrm{ab}$ \\
Glyphosate & $9,4 \mathrm{a}$ & $1,4 \mathrm{a}$ & $0,1 \mathrm{ab}$ & $0,3 \mathrm{~b}$ \\
Paraquat & $5,4 \mathrm{a}$ & $1,1 \mathrm{a}$ & $0,0 \mathrm{~b}$ & $0,3 \mathrm{~b}$ \\
\hline
\end{tabular}

${ }^{1}$ Médias seguidas por mesma letra minúscula na coluna não diferem entre si pelo teste de Tukey $(\mathrm{p} \leq 0,05)$.

Fonte: Elaboração dos autores.

Para a variável NFG por espiga de milho, houve interações entre os fatores estudados (Tabela 4). A cobertura nabo-forrageiro, em geral, garantiu maior NFG por espiga de milho, independentemente do manejo da cobertura, com aplicação do herbicida nicosulfuron (Tabela 4). Quanto maior a cobertura de solo, maiores serão os efeitos de inibição sobre plantas daninhas, podendo garantir maior tempo da cultura livre da interferência destas, favorecendo a cultura (CONSTANTIN et al., 2007).

Tabela 4. Número de fileiras de grãos por espiga, em função da cobertura de solo, manejo pré-semeadura da cultura e controle das plantas daninhas em pós-emergência.

\begin{tabular}{|c|c|c|c|c|c|c|c|c|}
\hline \multirow{4}{*}{$\begin{array}{c}\text { Manejo da } \\
\text { cobertura } \\
\text { de solo }\end{array}$} & \multicolumn{8}{|c|}{ Número de fileiras de grãos por espiga } \\
\hline & \multicolumn{2}{|c|}{$\begin{array}{l}\text { Lolium } \\
\text { multiflorum }\end{array}$} & \multicolumn{2}{|c|}{$\begin{array}{l}\text { Raphanus } \\
\text { sativus }\end{array}$} & \multicolumn{2}{|c|}{$\begin{array}{c}\text { Trifolium } \\
\text { vesiculosum }\end{array}$} & \multicolumn{2}{|c|}{ Pousio } \\
\hline & \multicolumn{2}{|c|}{ herbicida } & \multicolumn{2}{|c|}{ herbicida } & \multicolumn{2}{|c|}{ herbicida } & \multicolumn{2}{|c|}{ herbicida } \\
\hline & $\operatorname{Com}^{1}$ & Sem & Com & Sem & Com & Sem & Com & Sem \\
\hline Testemunha & $\mathrm{A} 14,4 \mathrm{a}^{2 \mathrm{~ns}}$ & A13,9 a & $\mathrm{A} 14,4 \mathrm{a} *$ & $\mathrm{AB} 13,2 \mathrm{a}$ & $\mathrm{A} 14,3 \mathrm{a}^{\mathrm{ns}}$ & A13,3a & $\mathrm{A} 13,6 \mathrm{a}^{\mathrm{ns}}$ & $\mathrm{BC} 12,6 \mathrm{a}$ \\
\hline $\mathrm{RsC}(*)$ & $\mathrm{A}^{3} 15,2 \mathrm{a}^{\mathrm{ns}}$ & A14,2a & $\mathrm{A} 14,4 \mathrm{ab}{ }^{\mathrm{ns}}$ & $\mathrm{A} 14,5 \mathrm{a}$ & $\mathrm{A} 13,3 \mathrm{~b}^{\mathrm{ns}}$ & A13,1a & $\mathrm{A} 13,0 \mathrm{~b} *$ & $\mathrm{C} 11,5 \mathrm{~b}$ \\
\hline $\mathrm{RcC}(*)$ & $\mathrm{A} 14,1 \mathrm{a}^{\mathrm{ns}}$ & A14,5a & $\mathrm{A} 14,7 \mathrm{a} *$ & $\mathrm{~B} 12,4 \mathrm{~b}$ & $\mathrm{~A} 14,0 \mathrm{a}^{\mathrm{ns}}$ & A13,8ab & $\mathrm{A} 13,2 \mathrm{a}^{\mathrm{ns}}$ & $\mathrm{BC} 12,4 \mathrm{~b}$ \\
\hline Glyphosate & $\mathrm{A} 14,2 \mathrm{ab}^{\mathrm{ns}}$ & $\mathrm{A} 14,2 \mathrm{a}$ & $\mathrm{A} 15,7 \mathrm{a} *$ & $\mathrm{AB} 14,0 \mathrm{a}$ & $\mathrm{A} 13,4 \mathrm{~b}$ ns & $\mathrm{A} 14,0 \mathrm{a}$ & A14,6ab* & $\mathrm{AB} 13,4 \mathrm{a}$ \\
\hline Paraquat & $\mathrm{A} 14,6 \mathrm{a}^{\mathrm{ns}}$ & $\mathrm{A} 14,4 \mathrm{a}$ & $\mathrm{A} 14,3 \mathrm{a}$ & $\mathrm{AB} 13,7 \mathrm{a}$ & $\mathrm{A} 14,5 \mathrm{a}^{\mathrm{ns}}$ & $\mathrm{A} 14,3 \mathrm{a}$ & $\mathrm{A} 13,5 \mathrm{a}^{\mathrm{ns}}$ & $\mathrm{A} 14,4 \mathrm{a}$ \\
\hline
\end{tabular}

(*) RsC e RcC: roçado sem e com cobertura, respectivamente. ${ }^{1}$ Com e sem aplicação de nicosulfuron; ${ }^{2}$ médias seguidas por mesma letra minúscula na linha comparam aplicação do herbicida entre culturas e ${ }^{3}$ antecedidas por mesma letra maiúscula na coluna comparam manejo das coberturas dentro de cada cultura de cobertura, não diferindo entre si pelo teste de Tukey ( $\mathrm{p} \leq 0,05)$; ${ }^{\text {ns }} \mathrm{e}^{*}$ não significativo e significativo, respectivamente pelo teste $\mathrm{t}(\mathrm{p} \leq 0,05)$, comparando com e sem herbicida dentro de cada cultura de cobertura.

Fonte: Elaboração dos autores.

Quando não aplicado o herbicida nicosulfuron em pós-emergência, houve maior NFG de milho na cobertura de azevém, enquanto que, o pousio, em geral, apresentou menor NFG por espiga de milho, independentemente do manejo adotado (Tabela 4). Segundo Agostinetto et al. (2000), o pousio quando composto principalmente por gorga (Spergula arvensis) apresenta taxa de decomposição mais rápida, com menor cobertura de solo, desfavorecendo a cultura.

$\mathrm{Na}$ comparação entre os manejos em cada cobertura de solo, a aplicação do herbicida nicosulfuron não modificou a variável NFG de milho, em todas as culturas de cobertura (Tabela 4). 
Entretanto, quando não associado nicosulfuron aos manejos da cobertura, a cobertura de nabo-forrageiro roçada com retirada da palha, proporcionou maior NFG de milho, superando o manejo onde foi feito roçada e mantida a palha sobre o solo (Tabela 4). A retirada da palha de nabo-forrageiro após roçada, não proporcionou a atividade alelopática e barreira física, principalmente no período inicial de desenvolvimento da cultura do milho. Segundo Wandscheer e Pastorini (2008), o sistema radicular desta espécie não apresenta atividade alelopática tão acentuada quanto a parte aérea.

Para a variável NGF, houve interação entre os fatores manejo da cobertura de solo e aplicação de nicosulfuron (Tabela 5). As coberturas de solo dessecadas com glyphosate não diferiram quanto ao uso de nicosulfuron em pós-semeadura, enquanto que para os demais manejos o uso de nicosulfuron favoreceu o NGF em espigas de milho. As coberturas manejadas com roçada e retirada da palha, simulando pastejo, proporcionaram menor NGF, quando aplicado ou não o herbicida nicosulfuron (Tabela 5).

Com relação ao NGE, houve interação entre os fatores culturas de cobertura e manejo da cobertura de solo (Tabela 6). Para esta variável também houve interação entre os fatores culturas de cobertura e aplicação de herbicida em pósemergência (Tabela 7).

Tabela 5. Número médio de grãos por fileiras em espigas de milho, em função do manejo pré-semeadura da cultura e controle das plantas daninhas em pós-emergência.

\begin{tabular}{ccllcc}
\hline \multirow{2}{*}{$\begin{array}{c}\text { Aplicação } \\
\text { nicosulfuron }\end{array}$} & \multicolumn{5}{c}{ Número médio de grãos por fileira } \\
\cline { 2 - 5 } & Testemunha & $\mathrm{RsC}\left(^{*}\right)$ & $\mathrm{RcC}\left(^{*}\right)$ & Glyphosate & Paraquat \\
\hline Com & $27,3 \mathrm{~A}^{1 *}$ & $22,5 \mathrm{C} *$ & $25,6 \mathrm{AB} *$ & $23,1 \mathrm{BC}$ & $27,0 \mathrm{~A}^{*}$ \\
Sem & $23,2 \mathrm{~A}$ & $17,5 \mathrm{C}$ & $19,2 \mathrm{BC}$ & $21,8 \mathrm{AB}$ & $24,3 \mathrm{~A}$ \\
\hline
\end{tabular}

(*) RsC e RcC: roçado sem e com cobertura, respectivamente. ${ }^{1}$ Médias seguidas por mesma letra maiúscula na linha não diferem entre si pelo teste de Tukey $(\mathrm{p} \leq 0,05)$; ns e * não significativo e significativo, respectivamente pelo teste $t(\mathrm{p} \leq 0,05)$.

Fonte: Elaboração dos autores.

Tabela 6. Número de grãos por espiga de milho, em função das culturas utilizadas como cobertura de solo e do manejo pré-semeadura da cultura.

\begin{tabular}{|c|c|c|c|c|c|c|c|c|}
\hline \multirow{3}{*}{$\begin{array}{c}\begin{array}{c}\text { Manejo } \\
\text { das coberturas } \\
\text { de solo }\end{array} \\
\text { Testemunha }\end{array}$} & \multicolumn{8}{|c|}{ Número de grãos por espiga } \\
\hline & \multicolumn{2}{|c|}{$\begin{array}{c}\text { Lolium } \\
\text { multiflorum }\end{array}$} & \multicolumn{2}{|c|}{$\begin{array}{l}\text { Raphanus } \\
\text { sativus }\end{array}$} & \multicolumn{2}{|c|}{$\begin{array}{c}\text { Trifolium } \\
\text { vesiculosum }\end{array}$} & \multicolumn{2}{|c|}{ Pousio } \\
\hline & 387,6 & $\mathrm{a} \mathrm{A}^{1}$ & 362,8 & a A & 356,5 & a A & 287,1 & $\mathrm{~b} \mathrm{AB}$ \\
\hline $\mathrm{RsC}(*)$ & 328,0 & a BC & 288,4 & a B & 267,3 & a $\mathrm{C}$ & 219,6 & $\mathrm{~b} C$ \\
\hline $\operatorname{RcC}(*)$ & 372,6 & $\mathrm{a} A B$ & 287,1 & $\mathrm{~b}$ AB & 316,3 & $a b B$ & 262,6 & b BC \\
\hline Glyphosate & 317,0 & a $\mathrm{C}$ & 352,3 & $\mathrm{a} A B$ & 302,4 & $\mathrm{a} A B$ & 306,3 & $\mathrm{a} A B$ \\
\hline Paraquat & 396,5 & a A & 364,4 & a A & 362,8 & $\mathrm{a} A B$ & 337,6 & $\mathrm{a} A$ \\
\hline
\end{tabular}

(*) RsC e RcC: roçado sem e com cobertura, respectivamente. ${ }^{1}$ Médias seguidas por mesma letra minúscula na linha e maiúscula na coluna não diferem entre si pelo teste de Tukey $(\mathrm{p} \leq 0,05)$.

Fonte: Elaboração dos autores. 
A cobertura do azevém, em geral, independente do manejo aplicado às culturas de cobertura, proporcionou maior NGE de milho, quando comparada às demais coberturas de solo (Tabela 6). Já comparando os diferentes manejos, todas as coberturas de solo reduziram o NGE de milho, quando roçadas com a retirada da palha. Alguns autores relatam baixa atividade alelopática no sistema radicular de plantas (EMETERIO;
ARROYO; CANALS， 2004; WANDSCHEER; PASTORINI, 2008).

A aplicação de nicosulfuron em pós-emergência do milho, independente das culturas de cobertura, proporcionou maior NGE (Tabela 7). Este resultado pode decorrer do maior controle das plantas daninhas, eliminando a competição com a cultura, conforme verificado por Jakelaitis et al. (2004).

Tabela 7. Número de grãos por espiga de milho, em função das coberturas de solo e controle das plantas daninhas em pós-emergência.

\begin{tabular}{|c|c|c|c|c|}
\hline \multirow[b]{2}{*}{$\begin{array}{l}\text { Aplicação } \\
\text { nicosulfuron }\end{array}$} & \multicolumn{4}{|c|}{ Número de grãos por espiga } \\
\hline & $\begin{array}{c}\text { Lolium } \\
\text { multiflorum }\end{array}$ & Raphanus sativus & $\begin{array}{c}\text { Trifolium } \\
\text { vesiculosum }\end{array}$ & Pousio \\
\hline Com & $383,2 \mathrm{~A}^{1} *$ & $381,7 \mathrm{~A} *$ & $340,4 \mathrm{~B} *$ & $321,0 \mathrm{~B} *$ \\
\hline Sem & $336,0 \mathrm{~A}$ & $280,3 \mathrm{BC}$ & $301,7 \mathrm{AB}$ & $244,5 \mathrm{C}$ \\
\hline
\end{tabular}

${ }^{1}$ Médias seguidas por mesma letra maiúscula na linha não diferem entre si pelo teste de Tukey ( $\left.\mathrm{p} \leq 0,05\right)$; ns e * não significativo e significativo, respectivamente pelo teste $\mathrm{t}(\mathrm{p} \leq 0,05)$.

Fonte: Elaboração dos autores.

Quando realizada a aplicação ou não do herbicida nicosulfuron, a cobertura do pousio proporcionou menor NGE de milho, quando comparada a cobertura de azevém, que proporcionou maior desempenho desta variável (Tabela 7). Esta resposta deu-se pela maior cobertura sobre o solo e pela liberação de compostos alelopáticos, que diminuiu a emergência de plantas daninhas. Outro fator que pode ter influenciado é a menor degradação da palha, pela maior relação $\mathrm{C} / \mathrm{N}$ do azevém (AGOSTINETTO et al., 2000), aumentando o período da atividade alelopática presente na cobertura. Outra possibilidade, é que a cobertura do solo proporcionou uma maior retenção de umidade e liberação/reciclagem de nutrientes, para disponibilizar para a cultura.

Para a variável produtividade de grãos houve interações entre os fatores testados (Tabela 8). $\mathrm{O}$ azevém e nabo-forrageiro foram as coberturas de solo que em geral proporcionaram maior produtividade de grãos, independente do manejo da cobertura, com aplicação do herbicida nicosulfuron
(Tabela 8). A produtividade de grãos de milho pode ser favorecida quando em sucessão com azevém (LLOVERAS-VILAMANYA, 1987) e brassicaceas (SILVA et al., 2006).

A menor produtividade de grãos de milho, quando o herbicida nicosulfuron não foi aplicado em pós-emergência, em geral, ocorreu no pousio, independente do manejo adotado. O percentual médio de perdas, no pousio foi de $45 \%$, quando comparado aos 31,38 e $22 \%$ de perdas de grãos milho semeado sobre cobertura de azevém, naboforrageiro e trevo-vesiculoso, respectivamente (Tabela 8).

Independente da aplicação de nicosulfuron, o manejo da cobertura com roçada e retirada da palha para todas as coberturas, proporcionou, em geral, menor produtividade de grãos (Tabela 8). Com este manejo, pode-se verificar a possibilidade de uma menor atividade alelopática no sistema radicular, menor retenção de umidade no solo, menor liberação de nutrientes pela ausência da palha e maior entrada de luz para o estabelecimento das plantas daninhas. 


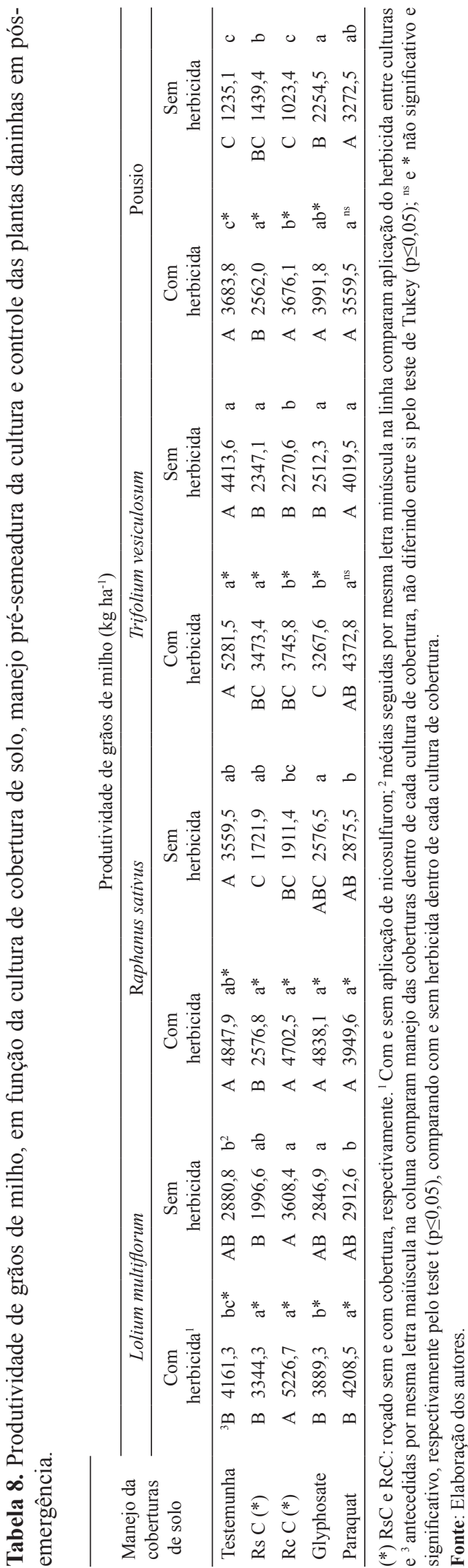

A aplicação de nicosulfuron pode auxiliar o efeito alelopático das plantas de cobertura no controle de plantas daninhas, refletindo na produtividade de grãos de milho. O nicosulfuron faz o controle das plantas daninhas existentes na área e a atividade alelopática das plantas de cobertura pode impedir a germinação de sementes presente no banco de sementes do solo ao longo da estação de crescimento da cultura. Este fato foi observado no presente trabalho, onde o controle de plantas daninhas em pós-emergência da cultura com o herbicida propiciou maior produtividade de grãos de milho, para todas as culturas de cobertura ou manejos realizados (Tabela 8). Estes resultados são semelhantes aos encontrados por Constantin et al. (2007), que verificaram que quando realizada aplicação de herbicida em pós-semeadura do milho, houve maior produtividade, independentemente do manejo adotado em pré-semeadura.

\section{Conclusões}

A cobertura de azevém, em geral, reduz o número de plantas daninhas emergidas e favorece o desempenho produtivo do milho.

O manejo das plantas de coberura com roçada e retirada da palha reduz a produtividade do milho.

A aplicação de nicosulfuron em pós-emergência possibilita maior produtividade do milho, independente da cultura de cobertura ou do manejo adotado.

\section{Referências}

AGOSTINETTO, D.; FERREIRA, F. B.; STOCH, G.; FERNANDES, F. F.; PINTO, J. J. O. Adaptação de espécies utilizadas para cobertura de solo no Sul do Rio Grande do Sul. Revista Brasileira de Agrociências, v. 6, n. 1, p. 47-52, 2000.

ALVARENGA, R. C.; CABEZAS, W. A. L.; CRUZ, J. C.; SANTANA, D. P. Plantas de cobertura de solo para sistema de plantio direto. Informe Agropecuário, Belo Horizonte, v. 22, n. 1, p. 25-36, 2001. 
ARAÚJO, A. G.; RODRIGUES, B. N. Manejo mecânico e químico da aveia preta e sua influência sobre a taxa de decomposição e o controle de plantas daninhas em semeadura direta de milho. Planta Daninha, Viçosa, MG, v. 18, n. 1, p. 151-160, 2000.

BALBINOT-JUNIOR, A. A.; MORAES, A.; BACKES, R. L. Efeito de coberturas de inverno e sua época de manejo sobre a infestação de plantas daninhas na cultura de milho. Planta Daninha, Viçosa, MG, v. 25, n. 3, p. 473-480, 2007.

BUENO, J.; AMIAMA, C.; HERNANZ, J. L. No-tillage drilling og Italian ryegrass (Lolium multiflorum L.): Crop residue effects, yields and economic benefits. Soil \& Tillage Research, Netherlands, v. 95, n. 1-2, p. 61-68, 2007.

CALVO, C. L.; FOLONI, J. S. S.; BRANCALIÃO, S. R. Produtividade de fitomassa e relação $\mathrm{C} / \mathrm{N}$ de monocultivos e consórcios de guandu-anão, milheto e sorgo em três épocas de corte. Bragantia, Campinas, v. 26, n. 1, p. 77-86, 2010.

CONSTANTIN, J.; OLIVEIRA, J. R.; CAVALIERI, S. D.; ARANTES, J. G. Z.; ALONSO, D. G.; ROSO, A. C.; COSTA, J. M. Interação entre sistemas de manejo e de controle de plantas daninhas em pós-emergência afetando o desenvolvimento e a produtividade do milho. Planta Daninha, Viçosa, MG, v. 25, n. 3, p. 513-520, 2007.

EMPRESA BRASILEIRA DE PESQUISA AGROPECUÁRIA - EMBRAPA. Centro Nacional de Pesquisa Agropecuária de Solos. Sistema brasileiro de classificação de solos. Rio de Janeiro: Embrapa, 2006. $412 \mathrm{p}$.

EMETERIO, L. S.; ARROYO, A.; CANALS, R. M. Allelopathic potential of Lolium rigidum Gaud. On the early growth of three associated pasture species. Grass and Forage Science, Oxford, v. 59, n. 2, p. 107-112, 2004.

FANCELLI, A. L.; DOURADO-NETO, D. Produção de milho. Guaíba: Agropecuária, 2000. 360 p.

FURLANI, C. E. A.; CORTEZ, J. W.; SILVA, R. P.; GROTTA, D. C. C. Cultura do milho em diferentes manejos de plantas de cobertura do solo em plantio direto. Revista de Biologia e Ciências da Terra, v. 7, n. 1, p. 161-167, 2007.

GOMES JUNIOR, F. G.; CHRISTOFFOLETI, P. J. Biologia e manejo de plantas daninhas em áreas de plantio direto. Planta Daninha, Viçosa, MG, v. 26, n. 34, p. 789-798, 2008.

JAKELAITIS, A.; SILVA, A. A.; FERREIRA, L. R.; SILVA, A. F.; FREITAS, F. C. L. Manejo de plantas daninhas no consorcio de milho com capim-braquiária
(Brachiaria decumbens). Planta Daninha, Viçosa, MG, v. 22, n. 4, p. 553-560, 2004.

JASPER, S. P.; SEKI, A. S.; SILVA, P. R. A.; BIAGgiOnI, M. A. M.; BENEZ, S. H.; COSTA, C. Comparação econômica da produção de grãos secos e silagem de grãos úmidos de milho cultivado em sistema de plantio direto. Ciência e Agrotecnologia, Lavras, v. 33, n. 5, p. 1385-1391, 2009.

LIEBMAN, M.; SUNDBERG, D. N. Seed mass affects the susceptibility of weed and crop species to phytotoxins extratcted from red clover shoots. Weed Science, Champaign, v. 54, n. 2, p. 340-345, 2006.

LLOVERAS-VILAMANYA, J. Forage production and quality of several crop rotations and pastures in northwestern Spain. Grass and Forage Science, Oxford, v. 42, n. 1, p. 241-247, 1987.

MAIGHANY, F.; KHALGHANI, J.; MOHAMMAD, A. B.; NAJAFPOUR, M. Allelopathic potential of Trifolium resupinatum L. (Persian clover) and Trifolium alexandrium L. (Berseem clover). Weed Biology and Management, Okayama, v. 7, n. 3, p. 178-183, 2007.

MONQUERO, P. A.; AMARAL, L. R.; INÁCIO, E. M.; BRUNHARA, J. P.; BINHA, D. P.; SILVA, P. V.; SILVA, A. C. Efeito de adubos verdes na supressão de espécies de plantas daninhas. Planta Daninha, Viçosa, MG, v. 27, n. 1, p. 85-95, 2009.

PALHARES, M. Distribuição e população de plantas e produtividade de grãos de milho. 2003. Dissertação (Mestrado em Agronomia) - Escola Superior de Agricultura Luis de Queiroz. Universidade de São Paulo, Piracicaba.

PRATES, H. T.; PAES, J. M. V.; PIRES, N. M.; PEREIRA FILHO, I. A.; MAGALHAES, P. C. Efeito do extrato aquoso de leucena na germinação e no desenvolvimento de milho. Pesquisa Agropecuária Brasileira, Brasília, v. 35, n. 5, p. 909-914, 2000.

RIZZARDI, M. A.; SILVA, L. F. Influência das coberturas vegetais antecessoras de aveia-preta e nabo-forrageiro na época de controle de plantas daninhas em milho. Planta Daninha, Viçosa, MG, v. 24, n. 4, p. 669-675, 2006.

SILVA, P. R. F.; ARGENTA, G.; SANGOI, L.; STRIEDER, M. L.; SILVA, A. A. da. Estratégias de manejo de coberturas de solo no inverno para cultivo do milho em sucessão no sistema semeadura direta. Ciência Rural, Santa Maria, v. 36, n. 3, p. 1011-1020, 2006.

SOUZA, L. S.; VELINI, E. D.; MARTINS, D.; ROSOLEM, C. A. Efeito alelopáico de capim-braquiaria (Brachiaria decumbens) sobre o crescimento inicial de sete espécies de plantas cultivadas. Planta Daninha, Viçosa, MG, v. 24, n. 4, p. 657-668, 2006. 
TIMOSSI, P. C.; DURIGAN, J. C.; LEITE, G. J. Eficácia de glyphosate em plantas de cobertura. Planta Daninha, Viçosa, MG, v. 24, n. 3, p. 475-480, 2006.

TOKURA, L. K.; NOBREGA, L. H. P. Alelopatia de cultivos de cobertura vegetal sobre plantas infestantes. Acta Science Agronomica, v. 28, n. 3, p. 379-384, 2006.
Potencial alelopático de cultivos de cobertura vegetal no desenvolvimento de plântulas de milho. Acta Science Agronomica, Maringá, v. 27, n. 2, p. 287-292, 2005.

WANDSCHEER, A. C. D.; PASTORINI, L. H. Interferência alelopática de Raphanus raphanistrum L. sobre a germinação de Lactuca sativa L. e Solanum lycopersicon L. Ciência Rural, Santa Maria, v. 38, n. 4, p. 949-953, 2008. 
